\title{
REVERSE INEQUALITIES OF ERDÖS-MORDELL TYPE
}

\author{
MEA Bombardelli AND SHANHE Wu
}

Abstract. This paper deals with the reverse inequalities of Erdös-Mordell type. Our result contains as special case the following reverse Erdös-Mordell inequality:

$$
R_{1}+R_{2}+R_{3}<\sqrt{2}\left(\rho_{1}+\rho_{2}+\rho_{3}\right),
$$

where $R_{i}$ and $\rho_{i}(\mathrm{i}=1,2,3)$ denote respectively the distances from an interior point $Q$ of $\triangle A_{1} A_{2} A_{3}$ to the vertexes $A_{1}, A_{2}, A_{3}$ and to the circumcenters of $\triangle A_{2} Q A_{3}, \triangle A_{3} Q A_{1}, \triangle A_{1} Q A_{2}$. Some other closely related inequalities are also considered.

Mathematics subject classification (2000): 26D05, 26D15, 51M16.

Keywords and phrases: Erdös-Mordell's inequality, Oppenheim's inequality, triangle, interior point, weight, exponent.

\section{REFERENCES}

[1] P. ERdös, Problem 3740, Amer. Math. Monthly, 42 (1935) 396.

[2] L. J. Mordell, D. F. BArrow, Solution of Problem 3740, Amer. Math. Monthly, 44 (1937) 252 254.

[3] O. Bottema, R. Z. Djordjević, R. R. Janić, D. S. Mitrinović and P. M. Vasić, Geometric Inequalities. Wolters-Noordhoff, Groningen, 1969.

[4] D. S. Mitrinović, J. E. PeČArić And V. Volenec, Recent Advances in Geometric Inequalities. Kluwer Academic Publishers, Dordrecht, Netherlands, 1989.

[5] D. S. Mitrinović, J. E. PeČArić, V. Volenec And J. Chen, Addenda to the Monograph: Recent Advances in Geometric Inequalities(I). Journal of Ningbo University, 4(2) (1991).

[6] A. OppenheIm, The Erdös inequality and other inequalities for a triangle, Amer. Math. Monthly, 68 (1961) 226-230.

[7] V. KomorniK, A short proof of the Erdös-Mordell Theorem, Amer. Math. Monthly, 104 (1997) 57 60.

[8] R. A. Satnoianu, Erdös-Mordell type inequality in a triangle, Amer. Math. Monthly, 110 (2003) 727-729.

[9] H. C. LENHARD, Verallgemeinerung und Verschärfung der Erdös-Mordellschen Ungleichung für polygone, Arch. Math., 12 (1961) 311-314.

[10] S. Gueron, I. ShAFrir, A weighted Erdös-Mordell inequality for polygons, Amer. Math. Monthly, 112 (2005) 257-263.

[11] D. S. Mitrinović, J. E. PeČARIĆ, On the Erdös-Mordell's inequality for a polygon, J. College Arts Sci., Chiba Univ., B-19 (1986) 3-6.

[12] A. AveZ, A short proof of a theorem of Erdös and Mordell, Amer. Math. Monthly, 100 (1993) 60-62.

[13] L. BANKofF, An elementary proof of the Erdös-Mordell theorem, Amer. Math. Monthly, 65 (1958) 521.

[14] N. Dergiades, Signed distances and the Erdös-Mordell inequality, Forum Geom., 4 (2004) 67-68.

[15] D. K. KAZARINOFF, A simple proof of the Erdös-Mordell inequality for triangles, Michigan Math. J., 4 (1957) 97-98.

[16] N. D. KaZarinoff, D. K. Kazarinoff's inequality for tetrahedra, Michigan Math. J., 4 (1957) 99104. 
[17] N. D. KaZARInOFF, Geometric Inequalities, New York: Random House, 1961, pp. 78-87.

[18] H. Ehret, An approach to trigonometric inequalities, Amer. Math. Monthly, 77 (1970) 254-257.

[19] H. LEE, Another proof of the Erdös-Mordell theorem, Forum Geom., 1 (2001) 7-8.

[20] G. Steensholt, Note on an elementary property of triangles, Amer. Math. Monthly, 63 (1956) 571572.

[21] C. Alsina, R. B. Nelsen, A Visual Proof of the Erdös-Mordell inequality, Forum Geom., 7 (2007) 99-102.

[22] L. CARLitz, Some inequalities for a triangle, Amer. Math. Monthly, 71 (1964) 881-885.

[23] H. BRABANT, The Erdös-Mordell inequality again, Nieuw Tijdschr. Wisk., 46 (1958/1959) 87.

[24] H. S. M. CoXeter, Introduction to Geometry, 2nd ed. New York: Wiley, 1969, pp. 9.

[25] L. FEJEs Tóth, Lagerungen in der Ebene, auf der Kugel und im Raum, 2nd ed. Berlin: SpringerVerlag, 1953.

[26] D. G. Kontogiannis, Equalities and Inequalities in the Triangle. Athens: Ekpaideutikis, 1996, pp. $127-128$.

[27] L. J. Mordell, On Geometric Problems of Erdös and Oppenheim. Math. Gaz. 46 (1962) 213-215.

[28] G. R. VeldKamp, The Erdös-Mordell inequality. Nieuw Tijdschr. Wisk., 45 (1957/1958) 193-196.

[29] S. Dar, S. Gueron, A weighted Erdös-Mordell inequality, Amer. Math. Monthly, 108 (2001) 165168.

[30] W. Janous, Further inequalities of Erdös-Mordell type, Forum Geom., 4 (2004) 203-206.

[31] S. Wu, L. Debnath, Generalization of the Wolstenholme cyclic inequality and its application, Computers \& Math. Appl. 53(1) (2007) 104-114.

[32] S. WU, Generalization and sharpness of the power means inequality and their applications, J. Math. Anal. Appl., 312 (2), (2005) 637-652. 